\title{
Trasplante combinado reno-pancreático
}

\author{
E. Cao Avellaneda, A.I. López López, A. Maluff Torres, P. López Cubillana,
}

M. Rigabert Montiel, L. Gimeno*

Servicio de Urología. *Servicio de Nefrología. Hospital Universitario Virgen de la Arrixaca. Murcia.

Actas Urol Esp 2005; 29 (7): 719

$\mathrm{M}$ ujer de 34 años de edad que presenta DM tipo 1 desde los 8 años e IR terminal secundaria a nefropatía diabética desde hace 10 meses. No otros antecedentes de interés. Se somete a trasplante reno-pancreático sin complicaciones en el postoperatorio inmediato, siendo alta a los 10 días postcirugía. En tratamiento con triple terapia inmunosupresora sin efectos secundarios de interés. En el momento actual, tras dos años de seguimiento, mantiene creatinina de $1,3 \mathrm{ng} / \mathrm{ml}$ y es insulinoindependiente.

\section{DISCUSIÓN}

El trasplante combinado reno-pancreático es el tratamiento de elección en pacientes diabéticos de larga evolución que sufren IRC terminal. Deben estar libres de patología vascular severa y tener una edad no superior a 50 años, aunque éste último criterio es cada vez más flexible. Se han realizado más de 10.000 trasplantes pancreato-renales en el mundo desde 1966, fecha del primer transplante de páncreas realizado en la Universidad de Minessotta. En nuestro hospital se han efectuado hasta la actualidad 8 trasplantes de este tipo.

Dr. E. Cao Avellaneda

C/ Mateos, no 1 - 9o

30002 Murcia

e-mail: enriquecao@hotmail.com

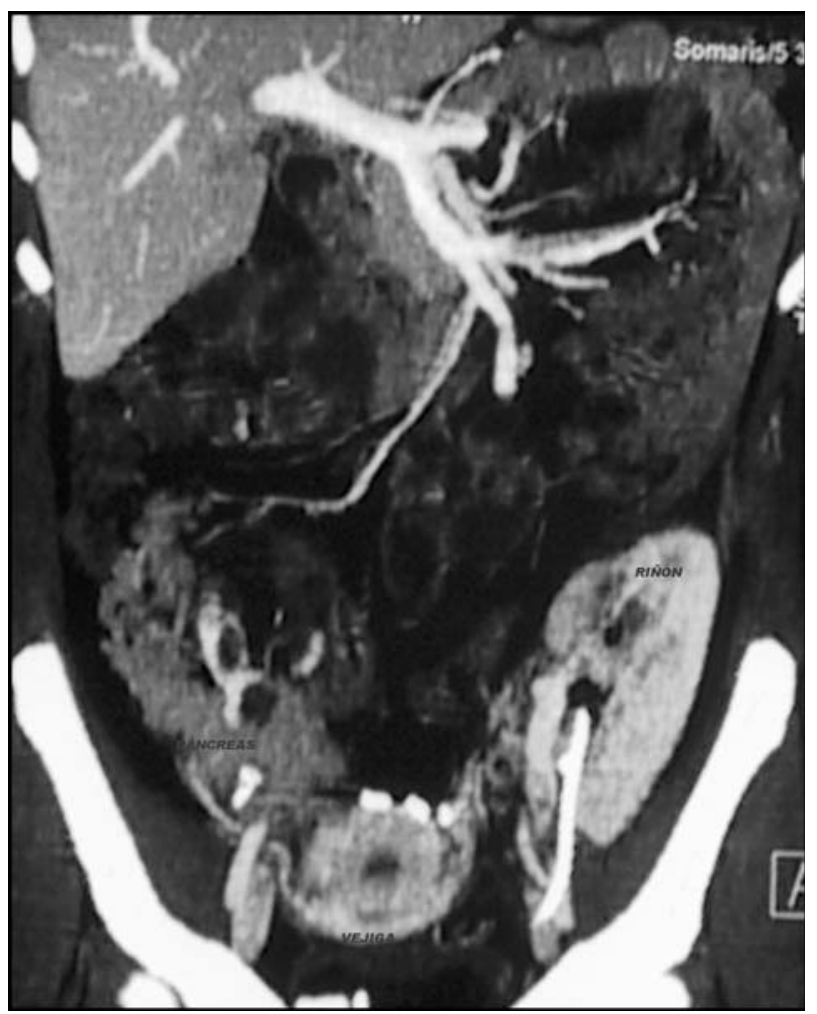

FIGURA 1 